\title{
Wyoming Basin Rapid Ecoregional Assessment
}

The overall goal of the Bureau of Land Management (BLM) Rapid Ecoregional Assessments (REAs) is to provide information that supports regional planning and analysis for the management of ecological resources. The REA provides an assessment of baseline ecological conditions, an evaluation of current risks from drivers of ecosystem change, and a predictive capacity for evaluating future risks. Additionally, the REA may be used for identifying priority areas for conservation or restoration and for assessing cumulative effects of multiple land uses.

There are several components of the REA. Management Questions, developed by the BLM and other agency partners for the ecoregion, identify the information needed for addressing land-management responsibilities. Conservation Elements represent regionally significant aquatic and terrestrial species, species assemblages, and biomes that are to be conserved and (or) restored. To assess the status of each Conservation Element, key ecological attributes (such as crucial wintering areas for mule deer or habitat connectivity for greater sage-grouse) are identified and evaluated. The REA also will assess major drivers of ecosystem change, called Change Agents, currently affecting or likely to affect the status of Conservation Elements in the future.

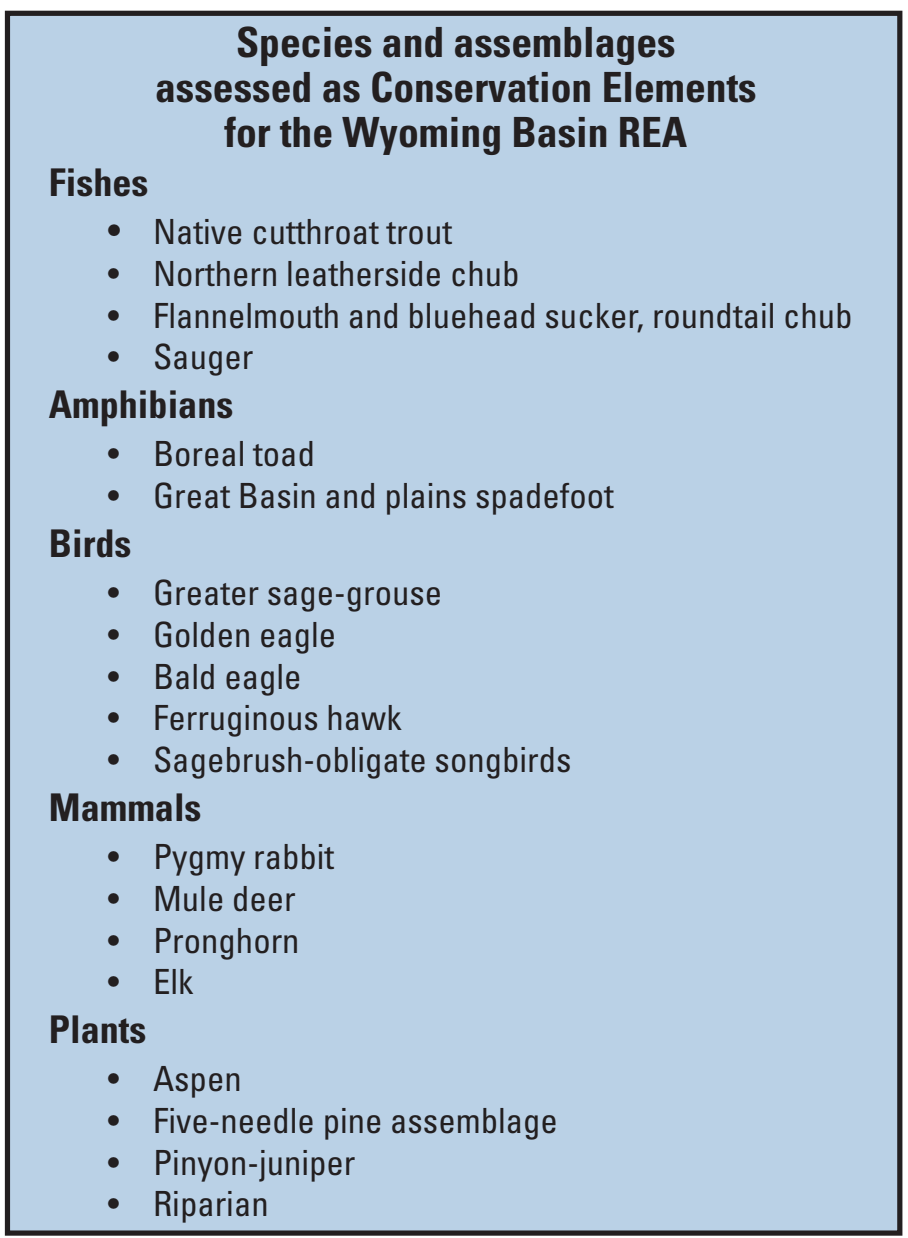

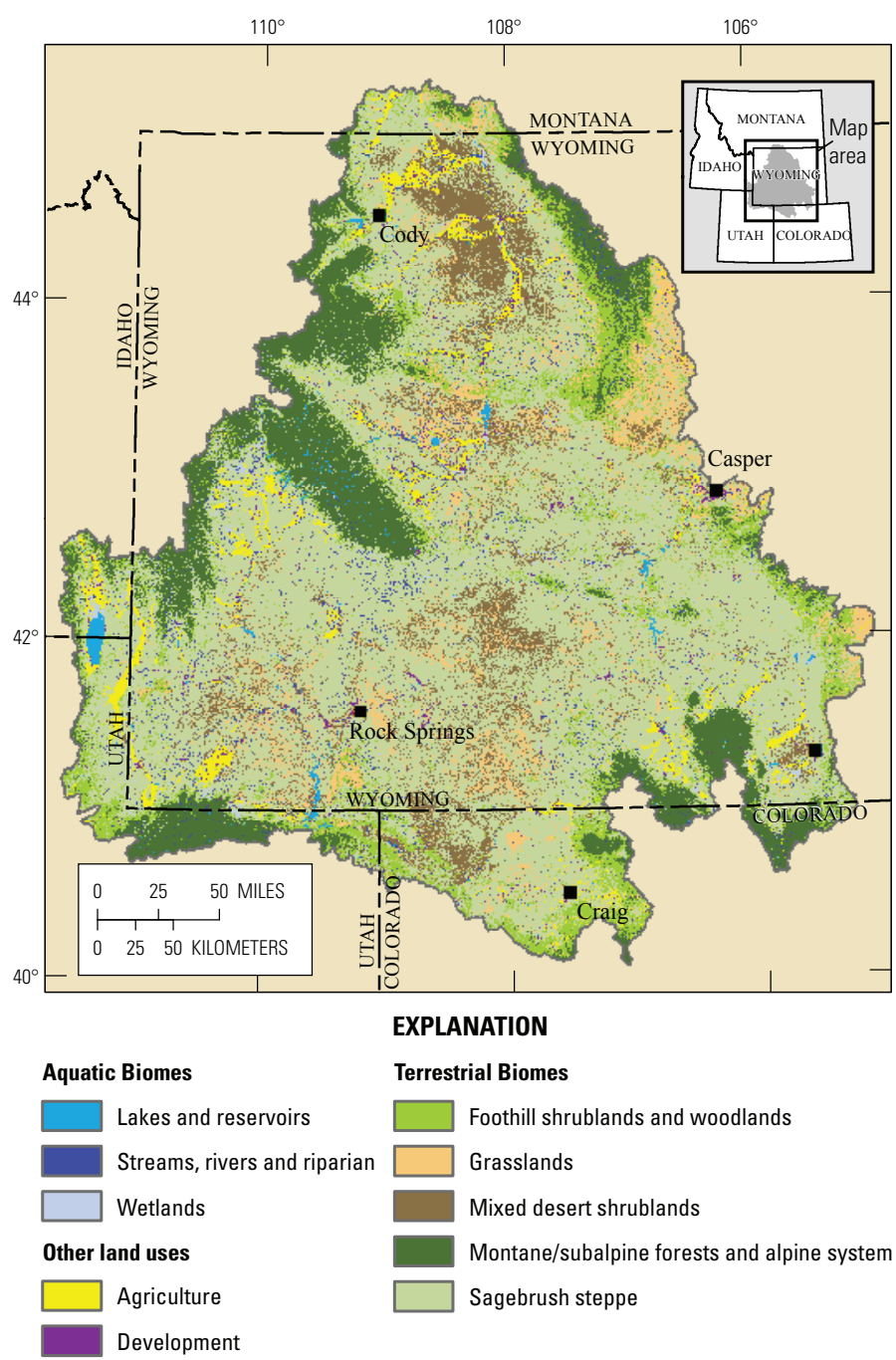

Biomes assessed as Conservation Elements for the Wyoming Basin Rapid Ecoregional Assessment.

The Wyoming Basin Ecoregion encompasses approximately 133,656 square kilometers and has some of the highest-quality wildlife habitats remaining in the Intermountain West, including intermountain basins dominated by sagebrush shrublands interspersed with deciduous and conifer woodlands and montane or subalpine forests at higher elevations. The Wyoming Basin also supports ranching and agricultural operations important to the region's economy. Fast-paced development of the region's abundant energy resources, including large natural gas reserves and areas of high wind-energy potential, is resulting in notable land-use effects, including habitat loss and fragmentation. 
The Wyoming Basin REA participants selected 8 major biomes and 19 species or species assemblages as Conservation Elements. The REA will address the four primary Change Agents required for the REA (development, fire, invasive species, and climate change). Additionally, insect pests and disease will be evaluated for some Conservation Elements.

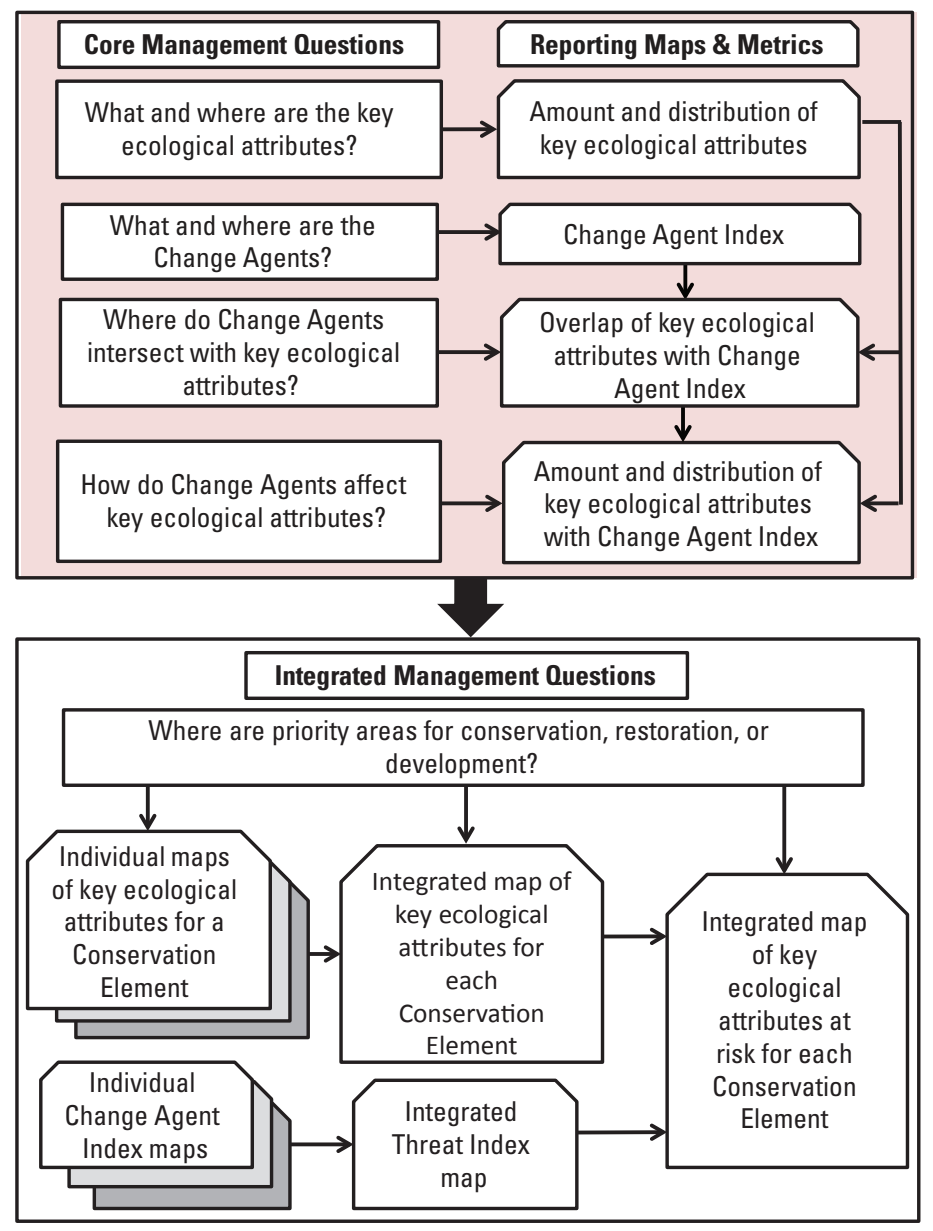

Generalized framework for addressing priority Management Questions for individual species, assemblages, and biomes (Conservation Elements). Examples of maps used to address both core and integrated Management Questions are included.

Key ecological attributes and threats from Change Agents will be evaluated and compiled into an integrated map of key ecological attributes at risk for each Conservation Element. The maps developed for assessing both core and integrated Management Questions can be used to address the goals of the REA at a number of levels: for individual species, species assemblages, biomes, aquatic and terrestrial systems, and for the entire ecoregion. This allows flexibility in how the products of the REA are compiled to inform planning and management actions across a broad range of spatial scales.

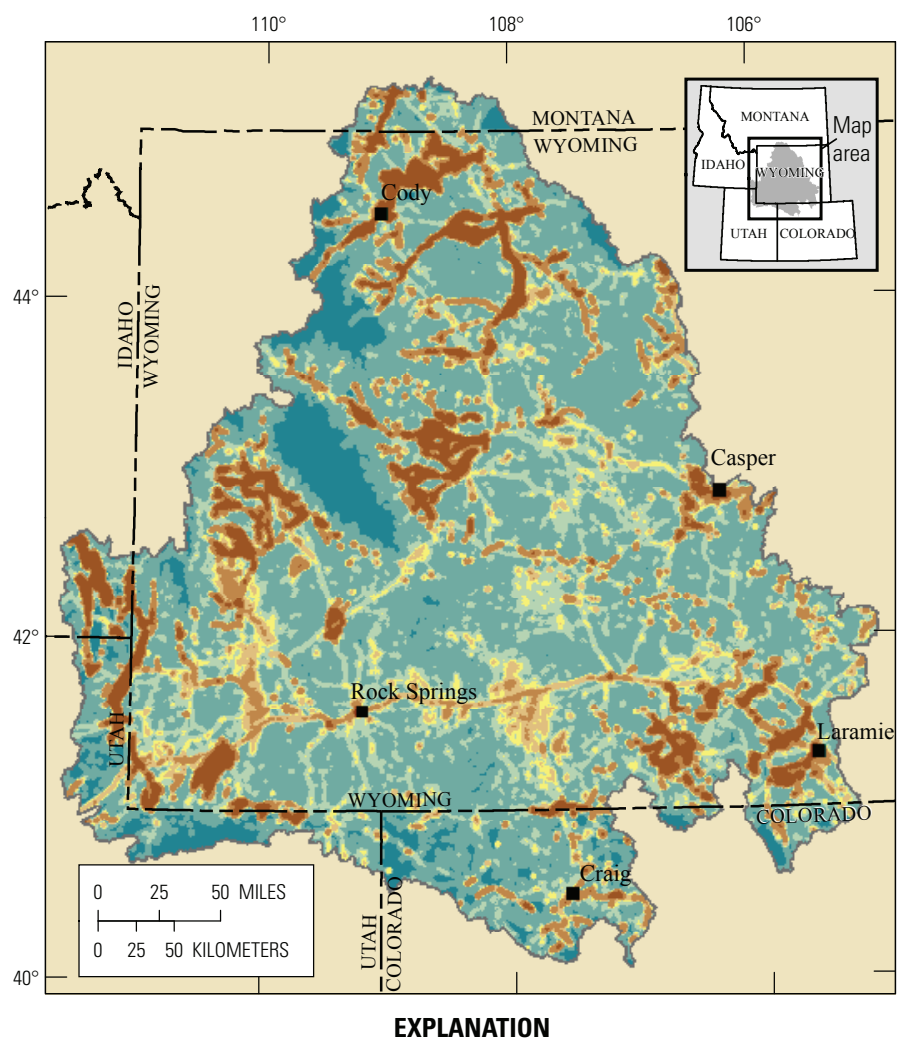

Terrestrial development index, in percent

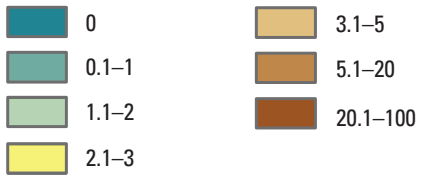

The terrestrial development index as applied to the Wyoming Basin Rapid Ecoregional Assessment. Development includes roads, railroads, energy and minerals development, urban areas, transmission corridors, and agriculture. Terrestrial development index scores are based on the total percent area of surface disturbance in a 16-square kilometer window (1,600 hectares).

Bureau of Land Management REA Web site: http://www.blm.gov/wo/st/en/prog/more/Landscape_Approach/ reas.html

\section{Contact Information}

\author{
Tasha Carr, Wyoming Basin REA Science Lead \\ U.S. Geological Survey \\ Fort Collins Science Center \\ (970) 226-9446 \\ carrn@usgs.gov
}
Bob Means, Wyoming Basin REA Project Manager
Bureau of Land Management
Wyoming State Office
(307) 775-6287
rmeans@blm.gov

